\title{
Direct marketing in health and medicine: using direct mail, email marketing, and related communicative methods to engage patients
}

\author{
James K. Elrod ${ }^{1}$ and John L. Fortenberry Jr. ${ }^{1,2^{*}}$
}

\begin{abstract}
Background: Direct marketing - the delivery of messages via mail, the Internet, and similar routes directly to consumers - is used extensively by healthcare organizations to attract and inform current and prospective patients of health and medical offerings and opportunities. Examples of direct marketing include direct-mail marketing, telemarketing, and Internet marketing, with routes being selected on the basis of their ability to reach desired audiences. The various avenues offered by direct marketing afford options to address most any sought group.

Discussion: Direct marketing is one of the most recognized forms of marketing communication, thanks in large part to its widespread use and direct engagement of consumers. While some applications clearly have the potential to irritate consumers (e.g., junk mail in post boxes, spam in email inboxes), direct marketing can be deployed in manners respectful of recipients and, in such cases, it can prove to be a helpful communications asset. To aid others in understanding this particular conveyance method, this article presents an overview of direct marketing and shares deployment insights and experiences from Willis-Knighton Health System.

Conclusions: Direct marketing provides a useful communications pathway, permitting health and medical institutions to educate and enlighten desired audiences. Given instances of overuse and misuse by organizations, however, great care must be taken to design and deploy direct marketing initiatives inoffensively. If well designed and respectfully implemented, direct marketing affords significant communications utility, earning a valued place in the marketing communications arsenals of healthcare establishments.
\end{abstract}

Keywords: Direct marketing, Marketing communications, Promotion, Hospitals, Healthcare

\footnotetext{
* Correspondence: john.fortenberry@lsus.edu

'Willis-Knighton Health System, 2600 Greenwood Road, Shreveport, LA

71103, USA

2LSU Shreveport, 1 University Place, Shreveport, LA 71115, USA
}

(c) The Author(s). 2020 Open Access This article is licensed under a Creative Commons Attribution 4.0 International License, which permits use, sharing, adaptation, distribution and reproduction in any medium or format, as long as you give appropriate credit to the original author(s) and the source, provide a link to the Creative Commons licence, and indicate if changes were made. The images or other third party material in this article are included in the article's Creative Commons licence, unless indicated otherwise in a credit line to the material. If material is not included in the article's Creative Commons licence and your intended use is not permitted by statutory regulation or exceeds the permitted use, you will need to obtain permission directly from the copyright holder. To view a copy of this licence, visit http://creativecommons.org/licenses/by/4.0/. The Creative Commons Public Domain Dedication waiver (http://creativecommons.org/publicdomain/zero/1.0/) applies to the data made available in this article, unless otherwise stated in a credit line to the data. 


\section{Background}

Patient acquisition and retention activities constitute some of the most important tasks conducted by health and medical establishments [1-6]. Without consistent and, ideally, growing patient volume, institutional viability becomes uncertain, potentially threatening the very existence of given medical providers and, in turn, the livelihoods of their employees and the health status of the people they serve [1, 7-9]. Seen in this light, inabilities to attract and retain patients carry consequences well beyond the walls of given healthcare establishments, extending deeply into markets and even impacting community health $[10,11]$. This fact, of course, provides significant motivation, compelling many healthcare providers to direct intensive efforts toward ensuring that ongoing streams of patients are secured, fostering viability that affords mutual benefits $[1,7]$.

In pursuing viable patient streams, communication proficiencies are essential, affording health and medical establishments with the ability to engage, inform, and attract current and prospective customers. Ultimately, this yields all-important patient volume and institutional market share [3, 5, 12, 13]. Pathways abound for reaching desired audiences, with one in particular, known as direct marketing, effectively delivering messages from given healthcare institutions directly to sought audiences, typically via mail, telephone, or Internet communications tools [1, 7]. Direct marketing is heavily utilized by health services organizations, with applications ranging from postcards mailed to prospects which introduce newly available medical technologies to emails which invite recipients to attend the open houses of given healthcare establishments [1, 5-8].

Direct marketing is one of the most recognized forms of marketing communication, thanks in large part to its widespread use and direct engagement of consumers. While some applications clearly have the potential to irritate consumers (e.g., junk mail in post boxes, spam in email inboxes), direct marketing can be deployed in manners respectful of recipients and, in such cases, it can prove to be a helpful communications asset [14-16]. To aid others in understanding this particular conveyance method, this article presents an overview of direct marketing and shares deployment insights and experiences from Willis-Knighton Health System.

\section{Definition and overview}

Direct marketing is one of many elements constituting the broad discipline of marketing, formally defined as "a management process that involves the assessment of customer wants and needs, and the performance of all activities associated with the development, pricing, provision, and promotion of product solutions that satisfy those wants and needs" [1], p. 288. Promotion, as evidenced in this definition, is a core feature of marketing, earning inclusion as one of the Ps in the classic expression known as the four Ps of marketing (i.e., Product, Price, Place, Promotion). The promotion aspect of marketing essentially entails any and all elements associated with engaging audiences, with the core pathways for engagement being depicted in a descriptive model known as the marketing communications (or promotions) mix [1, 17].

Classically illustrated, the marketing communications mix contains five principal avenues of communication; namely, advertising (i.e., the paid use of mass media to deliver messages), personal selling (i.e., the use of sales agents to personally deliver messages), sales promotion (i.e., the use of incentives, such as contests and free giveaways, to encourage patronage), public relations (i.e., the use of publicity and other unpaid promotional methods to deliver messages), and direct marketing (i.e., the delivery of messages via mail, the Internet, and similar routes directly to consumers) $[1,7]$. Healthcare providers examine each of these communicative avenues, selecting one or more believed to be most capable of reaching target audiences, with the ultimate goal being to encourage patronage or compel some other desired action $[1,9]$.

Direct marketing is characterized by its conveyance of information directly to individuals. Unlike advertising, which uses mass media to deliver messages to broad audiences en masse, hoping to entice interested parties into some form of desired exchange, direct marketing engages individuals directly by sending, for example, a promotional brochure, email message, or similar conveyance straight to the intended recipient. It is a highly targeted form of communication and, as such, is highly measurable, as responses to various solicitations can be tracked with relative ease [14-16, 18]. Historically, direct marketing often brought to mind telemarketing or direct mail, but times have changed. Today, telemarketing has been deemed by society to be so undesirable that its use is now highly regulated, diminishing opportunities and associated presence considerably. Even though direct mail often is characterized by recipients as junk mail, it continues to be used quite heavily, although shifts to electronic forms of communication have diminished its popularity. The Internet indeed has ushered in numerous direct marketing opportunities, ranging from email appeals to newsletter distribution to social media engagements. This particular avenue is evolving rapidly and almost certainly represents the future of direct marketing methods $[1,14,16]$.

One of the most critical tasks associated with direct marketing pertains to building lists of prospects who will be targeted with associated solicitations [5, 14, 15]. Prospect lists often are purchased from vendors who specialize in the provision of such, permitting healthcare 
establishments to designate recipient characteristics (e.g., ZIP code, gender, age, interests, etc.) and request lists of candidates meeting associated criteria. Although more labor intensive, health and medical institutions can opt instead to build their own lists. Assembling these lists typically begins by asking current customers if they would like to receive collateral, such as monthly newsletters, invitations to special events, promotional messages detailing new healthcare options, and so on, adding those desirous of such to a direct marketing database. Invitations to join mailing lists, subscribe to social media news conveyances, and the like also can be inserted into other marketing communications, with those opting in being added to associated direct marketing repositories. With concerted efforts over time, custom lists will grow and become true institutional assets, typically exceeding the value derived from their more generic, purchased counterparts $[5,7,14-21]$.

How lists are used arguably is just as important as quality of given lists. Simply collecting contact details and sending solicitations whenever healthcare institutions please is decidedly poor form and likely will engender the animosity of recipients. This practice historically has been used by many organizations and unfortunately continues to this day, perpetuating negative feelings regarding direct marketing [5, 7, 14-21]. Such animosity can be reduced or eliminated entirely by practicing what is known as permission marketing, requiring that institutions request and be granted permission before forwarding solicitations to intended recipients and, for those granting permission, offering easy methods to opt out of future solicitations [16, 22].

Delivery without permission to do so can damage institutional reputations and lead to senders being labeled "junk mailers," "spammers," and the like for directing unsolicited and often unwanted correspondence to individuals. As tempting as it might be to send promotional messages without an invitation, it should be avoided, as the main aim of healthcare communications rests with establishing a productive dialogue, a mission immediately destroyed by intruding on the personal space of audiences [5-7, 14-22]. Of course, beyond the assembly of lists and their proper use, the information contained in direct marketing pieces must have value to recipients. If healthcare providers develop direct marketing programs that fulfill these mandates, they can expect good things from their associated programs.

\section{Institutional background, deployment history, and context within marketing communications}

From its earliest of days, dating back to 1924, WillisKnighton Health System has emphasized communications excellence, something which in present times remains a strategic priority, compelling extensive communicative experimentation and innovation. Headquartered in Shreveport, Louisiana and situated in the heart of an area known as the Ark-La-Tex where the states of Arkansas, Louisiana, and Texas converge, Willis-Knighton Health System holds market leadership in its served region where it delivers comprehensive health and wellness services through multiple hospitals, numerous general and specialty medical clinics, an all-inclusive retirement community, and more. The institution's achievement of market leadership is attributed, in part, to communications prowess, permitting Willis-Knighton Health System to effectively engage current and prospective patients, evoking interest and attention, ultimately leading to burgeoning patient volume and customer loyalty.

Today, Willis-Knighton Health System leverages the power of the full marketing communications mix, deploying all of its components, including direct marketing. The establishment's use of direct marketing has been fairly consistent over its history, best characterized as a modest deployment, primarily used to complement other forms of marketing communication. Its use in this manner stems simply from Willis-Knighton Health System's preferences for other forms of marketing communication which, based on the institution's experiences, are more effective at achieving its designated communications goals. For direct marketing's part, associated applications deployed by Willis-Knighton Health System have evolved as the particular medium of communication and consumer preferences have advanced over time.

Of major forms of direct marketing, telemarketing, which entails contacting desired audiences via telephone, historically has been used sparingly by Willis-Knighton Health System due to the practice's disruptive nature. In recent decades, direct mail, which entails sending solicitations via post, has accounted for the majority of direct marketing deployments by the institution, with the typical application being in the form of postcards introducing new physicians, communicating new services, and so on to inform and enlighten recipients, as demonstrated by the example presented in Fig. 1. Willis-Knighton Health System's most prominent direct mail effort is the institution's healthy lifestyles magazine known as Vim \& Vigor [23]. This magazine features a variety of health and wellness stories, along with helpful details about WillisKnighton Health System and its associated services. Vim $\mathcal{E}$ Vigor is mailed to individuals and institutions throughout the Ark-La-Tex region and serves as a helpful vehicle for building and maintaining awareness.

Postal distribution of Vim \& Vigor is complemented by electronic distribution via Willis-Knighton Health System's website, with recent issues being viewable at the following link: https://www.wkhs.com/about/vim-vigor. This move was inspired by very clear trends which indicate increasing use of and preferences for Internet-based communications 

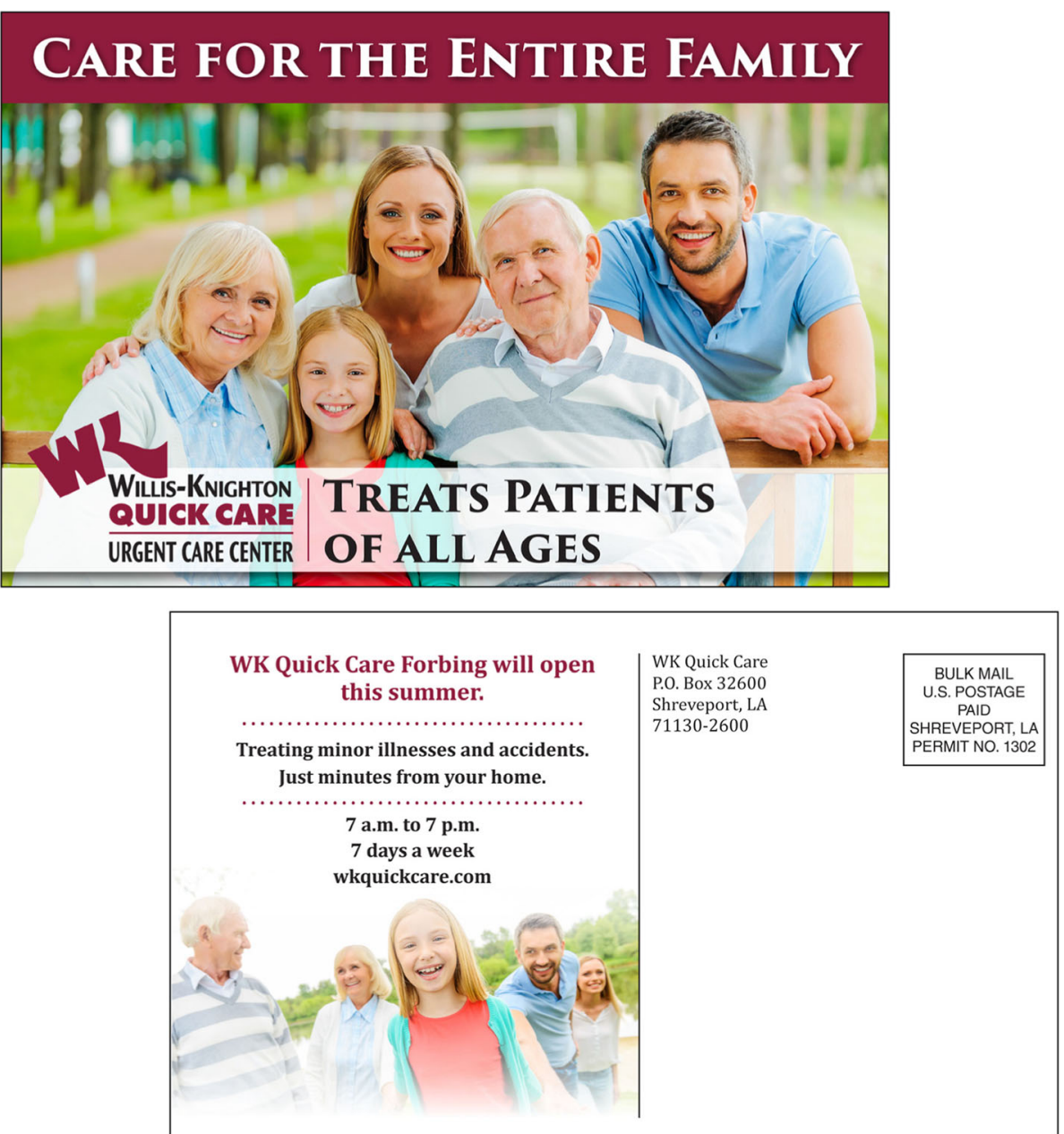

Fig. 1 A postcard promoting Willis-Knighton Health System's Quick Care Urgent Care Center

by consumers. This particular avenue of communication is capturing an expanding share of the institution's direct marketing dollar as paper-based and posted methods fall out of favor as Internet communications continue to develop and proliferate [3]. In keeping with this trend, Willis-Knighton Health System has directed more attention toward electronically-distributed direct marketing applications, with the most notable initiatives being email-directed communications and subscriptions to social media platforms, following a permission marketing protocol.

Although occupying a relatively small portion of WillisKnighton Health System's overall marketing communications budget, direct marketing is fulfilling its designated purpose, complementing other marketing communications deployed by the institution. The medium, of course, is capable of more robust deployments, with the method and manner of given applications being determined based on the wants and needs of particular establishments. Regardless of approach and intensity, care must be taken to ensure that deployments are respectful of recipients, something that is essential in order for direct marketing to fulfill its intended purpose of informing and enlightening recipients.

\section{Strengths}

Willis-Knighton Health System's observations from its direct marketing experiences suggest a number of strengths, compelling the avenue's inclusion in the institution's marketing communications mix composition. Chief strengths of direct marketing are described as follows.

\section{Ability to be precisely targeted}

As suggested by its name, direct marketing is forwarded directly to individual recipients, affording precise targeting which permits personalization and minimizes wasted circulation [5, 6, 14-21]. Something as simple as addressing a parcel using a person's actual name, as opposed to "Resident" or something equally nondescript, can improve the chances that the parcel will be noticed. This is all the more the case for more robust forms of customization, such as inserts which reference the 
recipient by name, and, with permission marketing elements in place, forwarding information for which the individual has already expressed an interest in receiving. Without such customization, direct marketing applications are more likely to be disregarded, constituting circulation which delivers no value. Since the goal of direct marketing is to engage, the investment required to compel someone to actually look at pieces received makes perfect sense. Doing the opposite and deciding to simply send generic parcels will foster inattentiveness and yield a diminished return on investment. As such, healthcare institutions engaged in direct marketing should take advantage of the communicative method's precision targeting capability and customize conveyances, accordingly.

\section{Highly measurable performance}

Unlike many forms of marketing communication, direct marketing happens to be highly measurable, something enhanced further by particular creative applications, permitting establishments to better determine return on investment [14-21]. Direct mail pieces, for example, can feature a particular telephone number in the given message, providing reasonable assurances that calls directed to that number were generated by the noted direct mail campaign. A newsletter distributed to recipients which conveys a special offer that is only promoted in the given communication provides similar opportunities to ascertain impact by tying results to the particular direct marketing campaign. Direct marketing applications placed via the Internet permit a wealth of tracking opportunities through such things as the inclusion of web links tied to given campaigns, the ability to access data analytics details, including recipient click behaviors, and more, giving perhaps the greatest utility for assessing campaign results. Such measurability aids in shaping and honing approaches by reviewing experiences of prior campaigns, making adjustments as needed for improvements in future campaigns. This also is most helpful in determining-and justifying-marketing communications budgets.

\section{Potential to convey significant information}

Direct marketing efforts have the potential to telegraph significant amounts of information $[5,6,14-21]$. Whereas a 30-second television commercial can only effectively convey a limited amount of detail, direct marketing, courtesy of its delivery methods, can feature a wide range of information. This is especially helpful in the health services industry where offerings typically are highly complex, necessitating robust details in order for consumers to make informed decisions. A direct mail parcel posted to residents might, for example, contain a multipage brochure, information booklet, or other form of collateral, conveying extensive facts and figures which can be consumed at the leisure of recipients. Internet communications offer the same potential, including the convenience of featuring helpful web links which can be directly accessed by the recipients of given communications. This particular attribute actually works quite well for reinforcing other forms of marketing communication, with advertising building top-of-mind awareness for, say, a given medical procedure, and a complementary direct marketing campaign delivering enhanced information to bolster awareness of the given innovation, yielding effective marketing communications synergies.

\section{Limitations}

Motivations to use direct marketing are counterbalanced by a series of limitations which must be factored into applications so as to minimize or avoid associated effects. Notable limitations are described as follows.

\section{Potential for intrusiveness}

Direct marketing, courtesy of its direct engagement attribute, has the potential to intrude on the privacy of recipients, something which is magnified when organizations carelessly and selfishly deploy the medium of communication [5, 6, 14-21]. Many have experienced, for example, unrelenting telephone solicitations, junk mail cluttering mailboxes and hampering one's ability to locate meaningful parcels, and spam messages crowding email inboxes and diminishing associated utility. Such nuisances have harmed the reputation of direct marketing, necessitating extreme care in its deployment. As described in prior sections, the potential for intrusiveness can be diminished or eliminated entirely with the establishment of a protocol which requires receipt of permission prior to forwarding direct marketing communications to targets. Doing so eliminates wasted circulation and ensures that direct marketing efforts are not reputationally damaging by overstepping the boundaries of recipients.

\section{Potential to be overlooked}

The volume of direct marketing efforts forwarded to consumers generally is staggering, overwhelming recipients who often will not take the time to separate meaningful and relevant communications from the many which are not. The end result of this proliferation is consumer inattentiveness to direct marketing appeals [5, 14-21]. This, of course, makes it very difficult for institutions forwarding targeted, relevant, and respectful direct marketing communications to break through the clutter to win the attention of recipients. Stories of people visiting their mailboxes, grabbing parcels, and disposing of junk mail without as much as a second glance abound, as do accounts of individuals opening their email inboxes and deleting messages en masse, not wishing to take the time to screen the sea of solicitations often flooding their accounts. Breaking 
through the clutter is challenging for anyone engaged in direct marketing, with perhaps the best method for doing so being through the deployment of highly creative applications which capture attention. These, of course, must be infused with communications which are relevant and delivered respectfully.

\section{Database management challenges}

As noted in prior sections of this article, the success of direct marketing campaigns is heavily reliant on the quality of the recipient list. Quality must extend beyond correct contact details, reaching into deeper things like communication preferences (e.g., mail, telephone, email), content desired (e.g., promotional messages from the host organization, promotional messages from partner organizations), relevance to the recipient (e.g., sports medicine services for athletically-inclined individuals, senior-related health services for senior citizens), and the like. These details must be managed properly and updated in a timely fashion, with this exercise representing a significant challenge [5, 14-21, 24]. Proper database management also is essential for ensuring that direct marketing permissions, which can and do change often, are accurate. Those opting in or opting out must be registered as such immediately as part of prudent efforts to ensure that audiences are addressed as they desire. Resources obviously are required for database management endeavors, ranging from information systems to personnel charged with overseeing and effecting processes. Despite associated challenges, such investments have the potential to dramatically improve direct marketing efforts.

\section{Operational reflections}

For administering any component of the marketing communications mix, Willis-Knighton Health System advises establishing a baseline foundation of resources, including (1) top leadership support and commitment, (2) financial resources sufficient for funding communications activities, (3) competent personnel charged with effecting given initiatives, and (4) formal processes permitting effective planning, implementation, and evaluation of initiatives. Adequate resources set the stage for productive audience engagement endeavors, minimizing chances of resource-depleting and reputationdamaging mistakes which, in the realm of marketing communications, often are very public, given the open circulation of such conveyances. These resources also ensure competencies in using given marketing communications mix components, with proper deployment being essential for realizing desired outcomes.

Beyond the advisories conveyed elsewhere in this article, Willis-Knighton Health System suggests that health and medical establishments considering the use of direct marketing make certain that they carefully consider the total costs of the particular applications under examination. Minimally, healthcare entities will need to consider the costs associated with (1) development of creative content, (2) production of associated collateral, such as printing in the case of direct mail, (3) purchasing or building a recipient list, including database management expenses, (4) distribution fees-such as postage in the case of direct mail-associated with forwarding direct marketing communications to recipients, and (5) labor costs associated with effecting given campaigns. Once expenditures are tallied, healthcare providers then are positioned to compare the costs of the proposed direct marketing campaign with the costs of other forms of marketing communication, providing a useful evaluative measure for marketing communications planning. Such examinations aid in ensuring that total costs are considered whenever contemplating direct marketing campaigns, permitting health and medical organizations helpful assistance in determining the most prudent avenues available for achieving designated communicative goals.

\section{Conclusions}

Direct marketing provides a useful communications pathway, allowing health and medical institutions to educate and enlighten desired audiences. This sets the stage for acquiring patronage and resulting market share, yielding numerous mutual benefits for given establishments and their communities. As with all forms of marketing communication, care must be taken to deploy direct marketing properly, capitalizing on its strengths while avoiding applications that evoke its limitations. Database assembly and management activities are particularly critical and a permission marketing mindset is imperative for achieving the best results. Further, given instances of overuse and misuse by organizations, great care must be taken to design and deploy direct marketing initiatives inoffensively. If well designed and respectfully implemented, direct marketing affords significant communications utility, earning a valued place in the marketing communications arsenals of health and medical organizations.

\section{Acknowledgments}

A special note of thanks is extended to Marilyn Joiner and the greater WillisKnighton Health System family for their helpful assistance throughout the development and publication of this article.

\section{About this supplement}

This article has been published as part of BMC Health Services Research Volume 20 Supplement 1, 2020: Marketing communications in health and medicine: perspectives from Willis-Knighton Health System. The full contents of the supplement are available online at http://bmchealthservres.biomedcentral.com/articles/supplements/volume-20-supplement-1.

\section{Authors' contributions}

The authors jointly developed the submitted manuscript, with each performing critical roles from early conceptualization through to the 
production of the full manuscript. The manuscript resulted from a collaborative effort. Both authors read and approved the final manuscript.

\section{Authors' information}

JKE is President and Chief Executive Officer of Shreveport, Louisiana-based Willis-Knighton Health System, the region's largest provider of healthcare services. With over 55 years of service at the helm of the institution, JKE is America's longest-tenured hospital administrator. A fellow in the American College of Healthcare Executives and honoree as a Louisiana Legend by Friends of Louisiana Public Broadcasting, he holds a bachelor's degree in business administration from Baylor University, a master's degree in hospital administration from Washington University School of Medicine, and an honorary doctorate of science and humane letters from Northwestern State University of Louisiana. He is the author of Breadcrumbs to Cheesecake, a book which chronicles the history of Willis-Knighton Health System. JLF Jr. is Chair of the James K. Elrod Department of Health Administration, James K. Elrod Professor of Health Administration, and Professor of Marketing in the College of Business at LSU Shreveport where he teaches a variety of courses in both health administration and marketing. He holds a BBA in marketing from the University of Mississippi; an MBA from Mississippi College; a PhD in public administration and public policy, with concentrations in health administration, human resource management, and organization theory, from Auburn University; and a PhD in business administration, with a major in marketing, from the University of Manchester in the United Kingdom. He is the author of six books, including Health Care Marketing: Tools and Techniques, 3rd Edition, published by Jones and Bartlett Learning. JLF Jr. also serves as Vice President of Marketing Strategy and Planning at Willis-Knighton Health System.

\section{Funding}

Article processing charges were funded by Willis-Knighton Health System.

\section{Availability of data and materials}

Not applicable.

\section{Ethics approval and consent to participate}

Not applicable.

\section{Consent for publication}

Figure 1 is published with permission of Willis-Knighton Health System. All required approvals for publication were obtained.

\section{Competing interests}

JKE and JLF Jr. are both employed with Willis-Knighton Health System.

Published: 15 September 2020

\section{References}

1. Fortenberry $\mathrm{JL} \mathrm{J}$. Health care marketing: tools and techniques. 3rd ed. Sudbury: Jones and Bartlett; 2010.

2. Feinberg D. Why advertise ... and why not? Mark Health Serv. 2011;31(2):3-5.

3. Elrod JK, Fortenberry JL Jr. Formulating productive marketing communications strategy: a major health system's experience. BMC Health Serv Res. 2018;18(Suppl 3):926.

4. Elrod JK, Fortenberry JL Jr. Billboard advertising: an avenue for communicating healthcare information and opportunities to disadvantaged populations. BMC Health Serv Res. 2017;17(Suppl 4):787.

5. Berkowitz E. Essentials of health care marketing. 4th ed. Burlington: Jones and Bartlett; 2017.

6. Thomas RK. Marketing health services. 3rd ed. Chicago: Health Administration Press; 2014

7. Fortenberry $\mathrm{JL} \mathrm{Jr}$. Cases in health care marketing. Sudbury: Jones and Bartlett: 2011.

8. Kotler P, Shalowitz J, Stevens RJ. Strategic marketing for health care organizations: building a customer-driven health system. San Francisco: Jossey-Bass; 2008.

9. Fortenberry JL Jr. Nonprofit marketing. Burlington: Jones and Bartlett; 2013.

10. Schiavo R. Health communication: from theory to practice. 2 nd ed. San Francisco: Jossey-Bass; 2014.

11. Parvanta CF, Nelson DE, Harner RN. Public health communication: critica tools and strategies. Burlington: Jones and Bartlett; 2018.
12. Elrod JK, Fortenberry JL Jr. Healthcare establishments as owner-operators of digital billboards: making the most of excellent roadside visibility and high traffic counts to better connect with patients. BMC Health Serv Res. 2018; 18(Suppl 3):928.

13. Elrod JK, Fortenberry $\mathrm{JL} \mathrm{Jr}$. Driving brand equity in health services organizations: the need for an expanded view of branding. BMC Health Serv Res. 2018;18(Suppl 3):924.

14. Nash E. Direct marketing: strategy, planning, execution. 4th ed. New York: McGraw-Hill; 2000

15. Stone B, Jacobs R. Successful direct marketing methods: interactive, database, and customer marketing for the multichannel communications age. 8th ed. New York: McGraw-Hill; 2008.

16. Kotler P, Keller KL. Marketing management. 14th ed. Upper Saddle River: Prentice Hall; 2012.

17. Elrod JK, Fortenberry JL Jr. Catalyzing marketing innovation and competitive advantage in the healthcare industry: the value of thinking like an outsider. BMC Health Serv Res. 2018;18(Suppl 3):922.

18. Perreault WD Jr, Cannon JP, McCarthy EJ. Basic marketing: a marketing strategy planning approach. 19th ed. New York: McGraw-Hill; 2014.

19. Belch GE, Belch MA. Advertising and promotion: an integrated marketing communications perspective. 11th ed. New York: McGraw-Hill; 2018.

20. Andrews JC, Shimp TA. Advertising, promotion, and other aspects of integrated marketing communications. 10th ed. Boston: Cengage; 2018.

21. O'Guinn TC, Allen CT, Scheinbaum AC, Semenik RJ. Advertising and integrated brand promotion. 8th ed. Boston: Cengage; 2019.

22. Godin S. Permission marketing: Turning strangers into friends and friends into customers. London: Simon and Schuster; 1999.

23. Elrod JK. Breadcrumbs to cheesecake. Shreveport: R\&R Publishers; 2013.

24. Tapp A, Whitten I, Housden M. Principles of direct, database, and digital marketing. 5th ed. London: Pearson; 2013.

\section{Publisher's Note}

Springer Nature remains neutral with regard to jurisdictional claims in published maps and institutional affiliations.

\section{Ready to submit your research? Choose BMC and benefit from:}

- fast, convenient online submission

- thorough peer review by experienced researchers in your field

- rapid publication on acceptance

- support for research data, including large and complex data types

- gold Open Access which fosters wider collaboration and increased citations

- maximum visibility for your research: over $100 \mathrm{M}$ website views per year

At $\mathrm{BMC}$, research is always in progress.

Learn more biomedcentral.com/submissions 